\title{
LUZ DA PEDRA
}

\section{Fernando Carlos Chamas}

Resumo: As lanternas de pedra são elementos tradicionais dos jardins de estilo oriental. $\mathrm{O}$ artigo introduz a exploração de seus signos na história, dos materiais às formas nas artes visuais, nas tradições religiosas orientais, e na ampliação de seus arquétipos culturais.

Palavras-chaves: escultura, lanternas de pedra, budismo, xintoísmo, Japão.

Abstract: The stone lanterns are traditional elements of oriental style gardens. The article introduces the exploitation of its signs in history, the material forms in the visual arts in Eastern religious traditions, and the expansion of their cultural archetypes.

Keywords: sculpture, stone lanterns, Buddhism, Shintoism, Japan.

Ninguém, pois, acende uma luzerna e a cobre com alguma vasilha, ou a põe debaixo da cama; põe-na, sim, sobre um candeeiro, para que vejam a luz os que entram. Porque não há coisa encoberta, que não haja de ser manifestada; nem escondida, que não haja de saber-se e fazer-se pública. (Lucas, VIII: 16-17).

\section{Introdução}

O uso da pedra como matéria-prima para a escultura não significava apenas o uso de um material disponível e primário, enquanto outras técnicas não tinham ainda sido descobertas ou aprendidas. De fato, sabemos que a pedra polida foi sendo desenvolvida, primeiramente, como arma para caça. Daí para grandes construções de pedra é um período histórico rápido e pouco explicado. Se considerarmos a arte egípcia e sua teologia da imortalidade, a pedra reunia as qualidades de durabilidade e grandiosidade, sendo a principal matéria-prima para sua arte, ao lado de outras 
tecnologias adiantadas dessa civilização. Para a arte, a matéria-prima já tem um propósito, já é a escolha de uma linguagem. As imagens de pedra normalmente se referem às imagens expostas às condições atmosféricas e à contemplação de massa, em oposição às imagens de outros materiais na antiguidade. Aquelas qualidades também foram procuradas em outras civilizações como um dos principais meios de propagação de uma ideologia quando ainda não existiam livros e muito menos pessoas letradas. As remotas civilizações indianas também conheceram o seu poder e foi lá que as estátuas budistas surgiram pela primeira vez, mil anos antes de chegar ao Japão, após incorporar crenças asiáticas milenares a sua iconografia.

O Japão, porém, embora utilizasse o barro e a terracota e fizesse círculos de pedra em sua pré-história, e há de se considerar a linguagem dos círculos de pedra como mundial, não teve uma arquitetura urbana e templos (religiosos e/ ou astronômicos) baseados na pedra como aconteceu nas antigas civilizações da América Central, Egito, Mesopotâmia, Índia e China. Não se encontram no Japão imensos monólitos, desses cujo peso e acabamento desafiam a ciência, e as "pirâmides" recentemente encontradas no fundo do mar leste do Japão ainda não são consideradas parte de sua história e talvez nem sejam ${ }^{1}$. Aconteceu que a influência chinesa sobre o Japão começou com a era do bronze, como que impedindo que os japoneses fossem, sozinhos, mais além com as pedras e mesmo o barro. Por outro lado, no Japão, a pedra ou a rocha não estavam sendo vistas como matéria-prima de construções ambiciosas, mesmo em relação aos templos. Seu papel foi originariamente sagrado e consagrado como habitação dos deuses (kami) sem a necessidade de uma intervenção radical na paisagem. Os budas de pedras esculpidos mais tarde apenas refletiam o que a crença nativa japonesa já acreditava sobre os elementos e os fenômenos naturais, o que não é incomum como um princípio de religiosidade. Porém, a forma como o budismo entrou no Japão, massiva e visualmente sofisticada, implica em uma diversidade de motivos para sua intensa disseminação além dos motivos políticos e dos próprios ensinamentos. Há razões em camadas mais profundas e sensíveis, e destaco, entre outras, o significado da luz.

1 Pirâmides submersas descobertas em 1985 na região no Arquipélago de Ryûkyû, a 480 km a sudoeste de Okinawa e datadas de 11 mil anos atrás. Existiu um Reino de Ryûkyû independente conhecido no ocidente como Reino de Léquias, em antigos relatos portugueses do século XVI, ocupando a maior parte do grupo de ilhas. Enquanto fato científico, não sabemos ainda se podemos considerar que houve grandes momumentos de pedra na região ou se é de uma história independente do Japão. 


\section{Budas luminosos de pedra}

Embora existam relativamente poucas esculturas em pedra no Japão, particularmente na forma de divindades populares tais como Jizô ${ }^{2}$, a corrente mais forte da escultura budista é sem dúvida a tradição da escultura em madeira e a valorização dessa rusticidade.

Considerando o material pela sua sensação de volume e massa, característica que será revalorizada no período Heian (794-1185) através da madeira, os budas escavados nas paredes das montanhas, em alto ou baixo relevo, sugerem que Buda é como uma montanha ou Buda como um deus da montanha, e que suas vestes fluem como uma cachoeira. $\mathrm{O}$ aproveitamento dos volumes da rocha das cavernas nos remonta à pintura rupestre pré-histórica e é, portanto, um passo característico da percepção artística. Essa primitiva manifestação nos ajuda a entender a sensibilidade estética como parte da natureza humana, e de como se liga não somente à sobrevivência (caça de bisões, por exemplo), mas também à vida anímica (sonhos, visões) que por abstração poderiam emergir de formas naturais. Baseado no animismo autóctone do Japão, um ser como Buda poderia ser representado nas rochas para ressaltar, abstratamente, a sua natural imponência e elevação sobre os homens, um passo a mais na arte, de outra mão também exaltando a natureza e, peculiarmente, com uma intervenção mínima, não exatamente monumental como os túmulos-colinas do período Kofun (300 d.C. a 500), exclusivamente xintoístas que, então, já existiam no Japão.

Budas de pedra são chamados de sekibutsu (石仏) e são largamente divididos em três categorias: as comparativamente pequenas, imagens de pedra simples, imagens esculpidas no interior de cavernas e as escavadas em relevo na superfície da pedra.

A pedra foi largamente usada pela escultura budista na China e na Coreia. $\mathrm{Na}$ China há numerosos templos imensos nas cavernas, grutas com uma entrada estreita, uma influência indiana direta. Na dinastia Tang (618-907), um novo estilo entrou em uso, no qual as imagens budistas foram esculpidas sobre rochedos e protegidos com uma construção de madeira.

As primeiras esculturas de outros materiais como barro e bronze serão semelhantes aos budas em alto-relevo em rocha das cavernas chinesas. Elas sugerem volume, mas são feitas para serem vistas de frente, muito esbeltas ou magras, como se fossem seres sobrenaturais tentando escapar dos limites impostos pela escultura em rocha, afinal, eram "obras divinas" nascidas nas montanhas.

2 Jizô é uma entidade budista da categoria bosatsu (do sânscrito bodhisattva), a personificações da compaixão, assim como Kannon, Monju, Fugen e outras inúmeras entidades. 
As imagens budistas esculpidas na face de uma rocha são denominadas de magai-butsu ${ }^{3}$ (磨崖仏), e normalmente foram feitas usando-se senkoku (線刻, linhas gravadas), ukibori (浮き彫り, relevos), saishiki (彩色, pigmentos coloridos) ou shippaku (漆箔, folhas de ouro aplicadas com laca). Essa prática floresceu nas dinastias Han (Kan, 206 a.C.-220 d.C.) e Norte-Sul da China (386-581). Grandes magai-butsu foram feitos em muitas regiões do Japão, mas depois do período Kamakura (1185-1334), foram feitos em menor escala.

O Japão teria recebido influências, mas devido à falta de rochas adequadas à escultura, essas grandes esculturas de pedra não foram realizadas em grande quantidade no Japão, o que não significa que a pedra não foi valorizada tanto quanto os outros materiais. Acredita-se que o uso da pedra para imagens budistas ${ }^{4}$ começou no Japão na última metade do século VII e no período Heian (794-1185). Pela primeira vez, nesse período, imagens foram esculpidas nas rochas.

Na província Daibu, há muitos budas de pedra do final do período Fujiwara (897-1185) até o período Muromachi (1334-1537). Dentre elas, a obra-prima é um grupo de sessenta imagens budistas de pedra em Usuki, na prefeitura de Ôita, Kyûshû. A estátua principal tem 278,8 centímetros com toques agudos de cinzel. Na produção de Ôyaishi, em Ôya, na província de Tochigi, há um grupo de estátuas que foram produzidas naquela época. Comparadas com as de Utsuki, têm uma aparência inferior, mas se observa as escalas grandiosas como na imagem central de 290 centímetros.

Exemplos de tais imagens são mais numerosas na província de Bungo, em Kyûshû como o Zutô (em Ôita), a imagem de Nyoirin Kannon, templo Hotsumisakiji. No século VI começam a surgir as lanternas de pedra e os Komainu (狛犬), um derivado do "cão coreano" de pedra, encontrado em átrios de grandes templos xintoístas no Japão, produzidos lá e até depois do período Kamakura (1185-1334).

Sanzon-seki (三尊石) são tríades de pedra em jardins de pedras que se assemelham às tríades de imagens budistas. Esses são tate-ishi (立石, “pedra em pé ou na vertical"), mas não três peças necessariamente. Esse estilo de arranjo de pedras aparece no período Heian (794-1185) e também são chamados de sanjin-seki (三 神石, “três divindades de pedra”) ou shugo-seki (守護石, “pedras guardiãs”), que provavelmente influenciaram os jardins de pedra Zen, mas mantinham o pensa-

3 Desejos (ganmon), poesia (shibun) e sutras (kyômon) esculpidas na face polida de uma rocha são chamados de magai.

4 Nos túmulos-colina do período primitivo japonês (Kofun, 300 d.C. a 500) foram encontrados ogros ou oni feitos de pedra, provavelmente para guardar esses mesmos túmulos, em comparação às figuras de terracota, haniwa, já sugerindo uma escolha de material para uma entidade e sua durabilidade. 
mento xintoísta. Veja as imagens, exemplos de força (1), volume (2), mimetismo (3), delicadeza (4) e idealização (5) na escultura budista em pedra no Japão.

Os jardins e parques são legítimos esforços em espelhar na terra os paraísos budistas, as "terras puras", o que os tornou peculiares do Japão, "o jardim japonês", associado a outros elementos como o bonsai, as lanternas de pedra, o lago com flores de lótus e elementos arquitetônicos relacionados à cerimônia do chá. Das esculturas em pedra, chegamos às lanternas de pedra cujas características afirmam um refinamento estético propiciado pelo budismo e intimamente associado a esse enquanto dentro da própria exploração artística do signo da iluminação espiritual.

\section{Análise dos ideogramas tôrô 灯籠 para lanternas}

Começando pelos ideogramas, o primeiro, 灯, é o fogo, já, de algum modo, condicionado como uma lâmpada ou lanterna. Já que o fogo produz luz e calor, fogo e luz podem ser tomados um pelo outro, mas o ideograma de luz é $k \hat{o}$ (光), muito usado no budismo, e o de fogo é $h i$ (火), enquanto um dos cinco elementos do taoismo (éter, fogo, ar, água, terra) e de outras crenças, como purificador e transformador. Imagens de maior hierarquia manifestariam o $k \hat{o}$, e outras, auxiliares poderosos - e absolutamente fora da visão judaico-cristã -, manifestariam o $h i$. A aura luminosa dos homens santos é, provavelmente, de uma visão anímica originariamente hindu a ser interpretada pelo ocidente e pelo oriente. É importante imaginar a aura tridimensionalmente, como uma cápsula, seja só na cabeça ou envolvendo todo o corpo.

O segundo ideograma, 籠, não é apenas o recipiente (“cesta, cesto grande, engradado; gaiola, caixa, cápsula"), mas também gera conceitos como "concentrar-se em, devotar-se a, impregnar-se com, inclinar-se, pairar sobre" e "envolver, esconder, encobrir, conter, encerrar, confinar-se em, fechar-se, tampar-se, trancar-se, isolar-se", que fazem lembrar tanto a introspecção em que Buda chegou à sua Iluminação quanto à reclusão da deusa xintoísta Amaterasu.

Enfim, tôrô significa "lanterna". Elas foram introduzidas no Japão juntamente com o budismo no século VI, da China para a Coreia, e desse para o Japão. Antigamente, era um costume construírem lanternas de pedra a céu aberto em frente aos templos budistas e xintoístas e foram numerosas e conhecidas como kentô (献 灯, “lanternas de oferenda”), que dá sentido ao tômyô (灯明) ou tômyôkuyô (灯 明供養), um “utensílio de ritual budista” (butsugu, 仏具) e de festivais religiosos xintoístas como uma luz oferecida aos deuses, uma luz votiva ou consagrada, que também simboliza os deuses e os ensinamentos budistas. Nelas podem ter gravadas sílabas sânscritas e imagens budistas. As maiores oferendas com lanternas ocor- 
rem na Montanha Koya no Hall das Lanternas (tôrôdô, 灯篭堂), em Wakayama, e no Festival das Dez Mil Lanternas (mandôe, 万灯会), em agosto, do Templo Tôdaiji, em Nara.

São muitos e menos comuns os ideogramas usados para essas lanternas como ou 灯篭, 燈篭, 灯楼: tôrô, 灯燈: tôtô e 灯炉: tôro. 灯楼 também é "a coluna” e 灯炉 é “o forno" do 灯明 (dito acima). Havia também os tôroden (灯炉 殿, “Pavilhão das Lanternas") que de acordo com as construções, fixavam-se no kidai (基台, base). Os daitôrô (台灯籠, “lanternas com pedestal”) são chamadas de okitôrô (置灯籠, “lanternas colocadas") e as penduradas de tsuritôrô (釣灯籠).

Surgirão armações e invólucros de materiais variados: seda (kentôrô, 絹灯 籠), papel (kamitôrô, 紙灯籠), bambu (taketôrô, 竹灯籠), pedra (ishitôrô, 石灯 籠), ouro (kinôro, 金灯籠), madeira (mokutôrô, 木灯籠), cobre (dôtôrô, 銅灯籠), ferro (tetsutôrô, 鉄灯籠), ouro e cobre (kondôtôrô, 金銅灯籠).

\section{Análise do sentido das lanternas}

Tentemos pensar como antes da invenção da luz elétrica. A luz depende de uma fonte e a primeira fonte de luz conhecida foi o fogo, e que o sol poderia ser uma bola de fogo, tomando-o como exemplo principal sem descartar outros fenômenos naturais com fortes conotações mitológicas como os relâmpagos, os vulcões, etc. Então, se, pela crença, os Budas emitem luz ${ }^{5}$, deve ser porque eles têm uma "chama própria", são Iluminados. Na pintura budista, a luz de Buda muitas vezes é representada como que espalhando cores pelo ar. A luz irradiada simboliza o esclarecimento trazido pelo ensinamento de Buda, revelando a ilusão da matéria por diluí-la como uma miragem. Assim como foi comum a associação das maiores divindades ao Sol, o maior de todos os Budas é chamado de "Grande Sol” (Buda Dainichi, 大日, 大: dai, grande; 日: nichi, sol). Mas os japoneses já tinham uma deusa da Luz na sua mitologia, Amaterasu Ômikami (天照大御 神). Após conflitos religiosos ${ }^{6}$, Dainichi e Amaterasu foram sincretizados. O

5 A característica de que o corpo de um Buda emite luz e que esta forma uma aura ao seu redor faz parte das 32 características básicas iconográficas e mitológicas que deveriam ser representadas em qualquer pintura e escultura. Para uma escultura, uma solução associada à devoção e aos valores aristocráticos foi revesti-la com ouro, ainda que iluminada pela luz natural ou por uma tocha.

6 Quando sutras e estátuas budistas foram introduzidas no Japão pelo reino coreano de Paekche no século VI, o clã Mononobe foi contra, rivalizando-se com o clã Soga, pró-budista e descendentes de coreanos. Buda, visto como um deus estrangeiro, provocaria a ira dos deuses nativos, os kami. Shôtoku Taishi, do clã Soga, será o príncipe divinizado pelo seu empenho em promover o budismo no Japão que significou orar pela saúde e prosperidade dos seus familiares e para o repouso dos espíritos dos ancestrais, mas sem questionar a legitimidade dos kami, ou seja, a própria origem da aristocracia. De fato, o budismo tenderá a se fundir ao xintoísmo considerando as divindades budistas como manifestações dos kami. 
$\mathrm{Kojiki}^{7}$ diz que Amaterasu, ao ver as maldades do irmão, fechou-se numa caverna e deixou o mundo na escuridão (um tipo de eclipse), até ser persuadida a sair.

Tanto para Cristo quanto para Buda, a Iluminação não era um diploma de mestre. Eles se tornaram mestres porque ensinaram coisas difíceis em formas simples e adequadas à época e lugar, como que equilibrando o grau de suas "luminosidades". Então devemos considerar "essa luz" como um fenômeno cujas proporções foram interpretadas pela teologia ou como um arquétipo para todo princípio de religiosidade humana.

Comparando-se com outras religiões, remotas ou atuais, não é difícil compreender o simbolismo da chama sobre a qual poderíamos discutir muito, mas nesse momento vamos nos deter em seu suporte que detém duas propriedades básicas: o elemento combustível e sua funcionalidade segundo o ambiente, ou seja, a lanterna não serve apenas para iluminar, mas também para decorar, função que mantém uma continuidade, mesmo com a ausência da chama que, nesse caso, fica reduzida a um propósito mais simples e não menos simbólico como o de gerar um ambiente acolhedor. Fontes luminosas nos atraem instintivamente e estão relacionadas com o despertar, a concentração, à vida. O "despertar" poder ser compreendido como o deleite da apreciação inteligente totalmente clara, sem que a mente gere a ilusão de uma realidade conveniente. As primeiras esculturas, para serem apreciadas em qualquer civilização, dependiam da luz do dia, ou à noite, das estrelas e da lua cheia, da luz trêmula de uma chama, o como essas esculturas deviam assim parecer vivas em suas cavernas, tumbas e templos, muito mais do que as dos museus atuais. Daí, o suporte da chama também ter conquistado um status sagrado. As lanternas de pedra (daitôrô), no oriente e, sobretudo no Japão, devem ser reconhecidas como parte da arte relacionada ao budismo e o estabelecimento simbólico de um "caminho de espiritualização".

\section{A estrutura das lanternas}

Os daitôrô (台灯籠) são geralmente formados de quatro partes (a partir de cima): (1). yane; (2). chûdai; (3). sao e (4).jirin. (Imagem 9).

(1). Yane (屋根, “cobertura, telhado"): formado pelo hôju e kasa e os detalhes kaen (火焔), kakikubi (欠首), ukebana (請花); kudarimune (降棟); warabide (蕨手).

O hôju (宝珠) tem a forma de uma cebola (entre bola e gota) e é colocada no topo do kasa (笠). Quando se trata de um objeto decorativo, usa-se o termo

7 Kojiki ("Registro de Coisas Antigas", 712), é a fonte mais importante de teologia xintoísta, que narra a origem divina dos imperadores 
giboshi (擬宝珠). Pode vir acolhida sobre uma base de pétalas de lótus em ukebana (請花). Hôju é uma gema sagrada, lit. um o bastão-jóia, mas em forma de bola ou gota. Outros nomes são nyôihôju (如意宝珠), hôshu (宝珠) ou nyôishu (如 意株) e o original sânscrito cintamani. Mani significa pedra preciosa ou pérola. É freqüentemente feita de bronze, encimada ou gravada com uma chama de três pontas ou halo de fogo ou chamas e pode vir sustentada por pétalas de lótus. Por sua luminosidade, representa Buda e a Lei. Sua pureza representa a verdade de Buda e a veracidade da Lei. Sua origem é diversa: do mar, do cérebro de Makara, do coração de Garuda ou do cérebro de Naga. Ela tem o poder de expulsar os demônios, purificar os pecados e realizar desejos. Essa forma também está no topo dos pagodes. Ela também é um atributo (jimotsu, 持物) de várias divindades que a possuem como Nyoirin Kannon (如意輪観音), Kichijôten (吉祥天), Batô Kannon (馬頭観音), Fugen (普賢), Monju (文殊), Hôshô (宝生), Jizô (地蔵). (Imagens 10 a 13).

Na Igreja Messiânica Mundial, a cintamani foi revivida pelas revelações de seu fundador, Mokiti Okada:

\begin{abstract}
Meu corpo abriga a Bola de Luz Divina conhecida desde a Antiguidade pela expressão "Cintamani" (palavra sânscrita utilizada para designar a fabulosa Bola de Luz detentora do Poder Divino)".[...] Em suma, é uma luz que Deus envia através do Elo Espiritual e não se pode afirmar que é algo que se assemelha à Imagem de Deus; é a própria Luz. Mas na verdade é uma coisa boa que o ser humano deve usar, pois através dela surge o poder divino. O Poder de Kannon é algo assim. ${ }^{8}$
\end{abstract}

Kannon é um bosatsu. Bosatsu, como dito na nota 2, é um ser iluminado pela sabedoria que decide ajudar a todos, mas para que sua Luz não "atrapalhe"

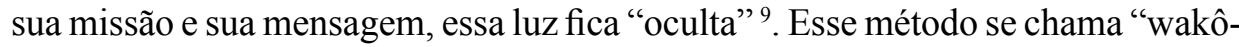
-dôjin ${ }^{10 "}$ que significa atenuante e "ocultando a sua inteligência e viver entre o povo na sociedade mundana". Para o Zen, isto também é a etapa final depois da iluminação, o que pode ser entendido como a urgência em "compartilhar a luz" sem o ego/desejo de ser reconhecido, e fazê-la despertar em outros seres.

(2). O Chûdai (中台) é formado pelo hibukuro e judai e pelos detalhes: higuchi (火口), ensô (円空), kamiku (上区), nakaku (中区) e shimoku (下区).

8 Extraído de entrevista registrada no Gokowa-roku n ${ }^{\circ} 12-03 / 06 / 1949$.

9 Esse é o pensamento budista Mahayana, contrário ao Hinayana cuja sabedoria atingida é, por si, intransferível, e erroneamente vista como uma corrente egoísta do budismo. Portanto, a palavra hinayana deve ser abolida, por ser pejorativa, utilzando-se o termo Theravada, "O ensinamento dos anciãos"

10 和光同塵 (Wakô Dôjin): tornar-se familiar com os seres sensíveis por moderação da gloriosa luz da santidade. Diz-se que Budas e Bosatsu ocultam sua glória dos seres sensíveis a fim de se tornar compreensível por eles, como um meio de salvá-los. Este conceito é aplicado à teoria dos Budas e Bosatsu manifestados como deuses xintoístas, kami. 
Chûdai: é a parte que sustenta o Hibukuro (火袋) e tem uma forma que espelha a parte mais baixa, o dai (台).

O Hibukuro (火袋) é o invólucro ao redor da chama. É a parte principal onde está a luz. Esta parte nunca pode ser omitida. Quando o objetivo é a ornamentação, não é necessário acender a luz, mas quando se procura a praticidade, a luz é acesa com fogo ou eletricidade.

Ukedai (受台) é o primeiro pedestal que recebe toda a primeira parte, o yane (屋根). Decora-se com formas de pétalas de flor de lótus (renben, 連弁) ou fendas (hazama, 狭間) com secções superior (上区), média (中区) e inferior (下 区), uma boca para o fogo (火口) e uma janelinha redonda (円空). Pode ter 4, 6 e 8 lados. Também denominada uke (受), ukehachi (受鉢), ukebana (請花), e como uma grande referência aos pedestais shumiza (須弥座) (imagens 14-16), "O Assento de Buda".

(3). Ashi (脚) formado pelo sao e o detalhe fushi

O ashi, “perna ou pé” ou sao (竿 ou 棹), “poste ou haste”, é a parte da coluna mais comprida que sustenta todas as partes superiores. Nas lanternas de altura baixa, representada pelo yukimikata (雪見型), é bem omitida. São em geral cilíndricos, mas também há os de 4, 6 e 8 lados. É muito usada uma decoração chamada fushi (節), nós.

(4). Dai (台): formado pelo chirin ou jirin (地輪) e o detalhe kaeribana. O dai é o segundo pedestal ligado diretamente ao chão (chi, 地). Sendo o alicerce, é também chamado de kiso (基礎) e, às vezes, kidan (基壇) em referência ao alicerce dos altares budistas ou à parte mais baixa. Espelhando o ukedai, pode assumir a mesma forma circular (rin, 輪) o de polígono e ter as pétalas de lótus invertidas, o kaeribana (反花).

O tsuritôrô (釣灯籠) é um estilo que retirou o pedestal e incorporou o tsurikan (釣環) nas pontas ao redor. Em geral, são circulares ou de 4, 6 e 8 lados. Em sua origem, são os seres Yasha (夜叉), Tentôki (天灯鬼) e Ryûtoki (竜灯鬼) que carregam os 灯籠 no lugar do sao (竿). Eles são pequenas criaturas, originalmente demônios que, agora salvos, carregam lanternas para iluminar o caminho em frente ao Buda. As estátuas originais estão no Templo Kôfukuji, Nara, e datam do Período Kamakura, 1215, feitas de madeira e com cerca de 80 centímetros de altura (imagem 17).

\section{Exemplos e desdobramentos}

São poucos os exemplares remanescentes mais antigos como o do Templo Asukadera (飛鳥寺) e o do templo Taimadera (当麻寺). Passou-se muito tempo sem fazê-los, mas tornaram a ser construídos depois da idade média japonesa (ca. 
1185-1615) e se tornaram um dos utensílios tradicionais do Japão. Começou com as portáteis e dobráveis, com armações de arame ou madeira, as andon (行灯), que originou as bonbori (雪洞) e as chôchin (提灯, lanternas de papel) para iluminar o caminho, a entrada e recintos dos templos, cômodos (okitôrô, 置灯籠 e tsuritôrô, 釣灯籠), casa de chá, jardins, estradas, portos. Essas lanternas são as mais características e conhecidas. Também foram usados como castiçal (tôdai, 灯台 ou 燈台 ou shokudai, 蜀台). Para combustão foram usados óleo e vela. Atualmente há os elétricos e os de gás propano. Nos parques e jardins japoneses tornaram-se elementos de decoração para serem contemplados e admirados. São muitos os de granito e sienito nos rios.

Há a de metal, como o de oito lados, de ouro e cobre, com mais de quatro metros de altura em frente ao Hall do Grande Buda (大仏殿) do Templo Tôdaiji (東大寺). Há também no templo Kôfukuji (興福寺), um de ferro no templo Kanshinji (観心寺), um no templo xintoísta Kasuga Taisha (春日大社), uma das mais antigas. No Museu Nacional de Tóquio há lanternas de ferro penduradas dos períodos Muromachi (1334-1537) e Momoyama (1537-1603).

Há cerca de nove categorias maiores e 75 subcategorias de lanternas. A lanterna do templo Kasuga é representativa como a forma 1. kasugakata (春日 型), pois são muitas desse tipo que estão na entrada de templos e sua praticidade é a altura. O sao (竿) é comprido e é uma peculiaridade o hibukuro (火袋) numa posição alta. Em geral estão instaladas alinhadas nos caminhos de um parque. A lanterna do tipo 2. yukimikata (雪見型) vem da palavra uwami (浮見), que significa "ver flutuar". Para que não tenha o sao (竿) e o chûdai (中台), a altura é baixa. A parte do kasa (笠) é grande porque são, sobretudo, usadas para iluminar a superfície da água e são muitas as que estão na beira d'água. A lanterna 3. kôkata (岬型) são as que removem a parte kiso (基礎) da lanterna yukimikata (雪見型) e imita o tôdai (灯台). A lanterna 4. oribeshiki (織部式) são as lanternas concebidas por Furuta Oribe (古田織部), um devoto da cerimônia do chá do Período Edo (1603-1868). Usa-se como um vaso (hachi, 鉢) lumionoso de tsukubai (蹲, a bacia de pedra). É um estilo cheio de vida que tem o hibukuro (火袋) de quatro lados. Para isso, o ajuste da altura é possível. No sao (竿) é peculiar ocorrer a evidência da influência cristã contendo uma imagem da Virgem Maria ou Cristo, sendo chamadas de Lanterna Maria (mariatôrô, マリア灯籠) e Lanternas Cristãs (kirishitantôrô, キリシタン灯籠). São usados em roji (露地, jardim ao lado do local da cerimônia do chá).

As 5. Bontôrô (盆灯籠) são lanternas decoradas para o Festival das Lanternas em fevereiro e agosto, como as duas mil lanternas de pedra do Templo Kasuga. As 6. Tôrônagashi (灯籠流し) são as lanternas que flutuam n'água no Festival Bon. 7. Nendogorintôba (粘土五輪塔婆) são as lanternas feitas de barro (nendo) na forma de um pagode (tô) de cinco ( go) andares ou anéis (rin). O ultimo ideograma, 
婆, significa “anciã”. 8. Ruritôrô (瑠璃灯篭) são lanternas penduradas feitas em lápis-lazúli. 9. Tôshoku (燈蜀) são as lanternas funerárias.

\section{Considerações finais}

Todas estas estruturas e detalhes são mais bem compreendidas se comparados às estruturas complexas e simbólicas dos pagodes ou estupas e dos pedestais das estátuas budistas, geralmente pedestais de lótus. A luz pode ser vista como uma linguagem universal, não apenas como indispensável à vida, mas também como símbolo de magia, civilização e religiosidade. Hoje, a tecnologia da luz elétrica tenta se aproximar ao máximo da luz natural e o estudo da luminosidade e do material das superfícies iluminadas são essências para a economia e para efeitos estéticos desejáveis. Imagens budistas em cristal ou vidro iluminados por dentro parecem realizar ideais antigos com novos materiais. Mais uma vez a ciência e o esoterismo do budismo se encontram e provam que as subpartículas elementares do átomo são de pura energia não localizável, pulsante e, enfim, toda a matéria é apenas uma aparição mais intrigante e fantástica do que os próprios fenômenos sobrenaturais. Juntar a luz a qualquer material é, nesse sentido, apenas unir dois estados extremos de matéria. Associado intimamente à luz, seu significado simbólico em diferentes épocas e lugares parece permanecer no sentido da lucidez espiritual, mas foi no budismo e na sua arte que as lanternas mais desenvolveram e conquistaram um espaço na mitologia mundial. Podemos afirmar que uma lanterna de pedra é uma representação de Buda e do potencial humano à Iluminação.

\section{Referências Bibliográficas}

\section{Livros:}

EGAMI, Namio. The Beginnings of Japanese Art. ("As Origens da Arte Japonesa”). Trad. John Bester. New York: Weatherhill - Visão da Arte Japonesa / Tôkyô: Heibonsha, 1976. v. 2.

\section{江上波未 「日本美術の誕生」日本の美術2 平凡社版 東京 1976}

SAWA, Ryûken. (comp.). Butsuzô Annai. (“Guia de Estátuas Budistas”). Tôkyô: Yoshikawa Kôbunkan, 1972.

佐和隆研「仏像案内」東京吉川弘文館 1963

TSUKAMOTO, Yoshitaka. (comp.). Bukkyô Daijiten Mochizuki. (“Grande Dicionário Budista Mochizuki”). Tôkyô: Sekai Seiten Kankôkyôkai, 1967.

塚本善隆「望月仏教大辞典」東京 世界聖典刊行協会 1967 


\section{Internet:}

灯籠. Wikipédia (ウィキペディア). Disponível em <http://ja.wikipedia.org/wiki/\%E7\%81\% AF\%E7\%B1\%A0>. Acesso em 12, dez, 2011.

As pirâmides submersas no Japão. Descobrindo a Vida. DCS LIVE. Disponível em <http:// dcslive.blogspot.com.br/2010/01/as-piramides-de-11-mil-anos-submersas.html>. Acesso em 18, nov, 2013.

\section{Entrevista transcrita:}

OKADA, Mokiti. Wakô-Dôjin. Gokowa-roku no 12 - 03/06/1949.

\section{Agradecimento:}

A Stone \& Design (Av. Pedro Aleixo, 785 Cachoeira do Campo - Ouro Preto/MG) criada pelo Escultor e Stone Designer Márcio Sodré, tendo como parceiros os Escultores Ernane Lima, Monge Ho Shokan e Milton Galdino e que me consultou também como parceiro em 2010. < http://www.lanternadepedra.com.br/>

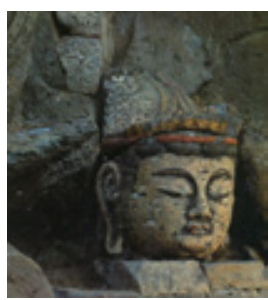

(1)

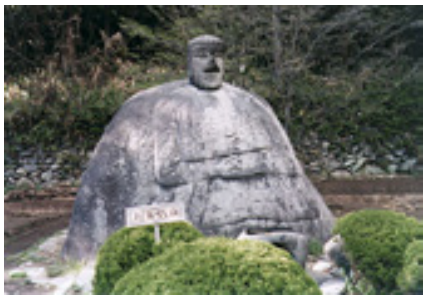

(2)

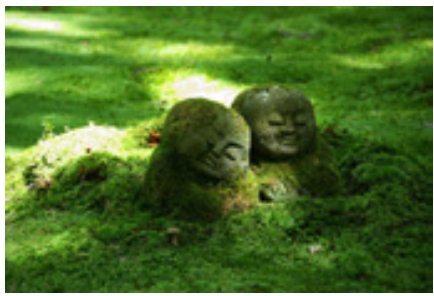

(1) Cabeça de Buda, pedra, séc. XII, 66,7 cm, Usuki, Oita.

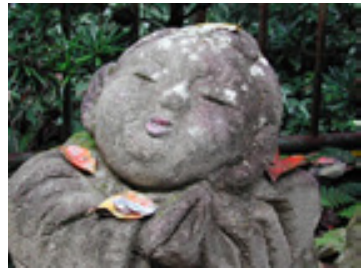

(4)

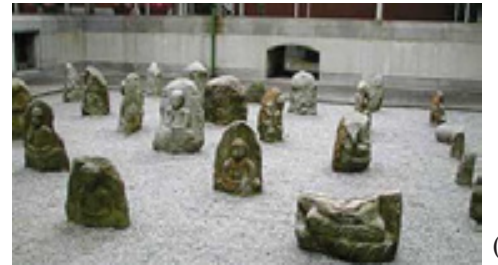

(2-5) sem referências (imagens de magai-butsu no Japão, imagens Google.) 

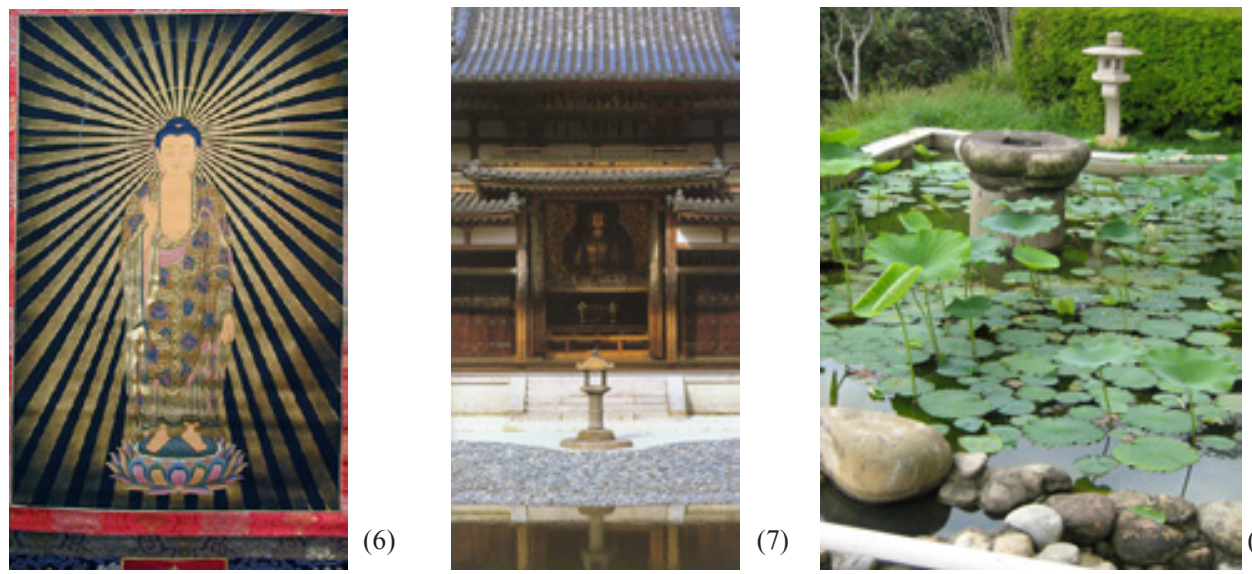

(6) A aura ou auréola de uma Buda ("como uma lanterna")

(7) Entrada do Templo Byôdô-in, em Kyôto, com uma lanterna na frente.

(8) Lago de Lótus com lanterna de pedra, São Paulo, SP-Cotia, com lanterna ao fundo.
a) kaen (火焔)
b) kakikubi (欠首)
c) ukebana (請花)
d) kudarimune (降棟)
e) warabide (葻手)
f) higuchi (火口)
g) ensô (円空)
h) renben (蓮弁)
i) fushi (節)
j) kaeribana (反花)
k) kamiku (上区)
1) nakaku (中区)
m) shimoku (下区)

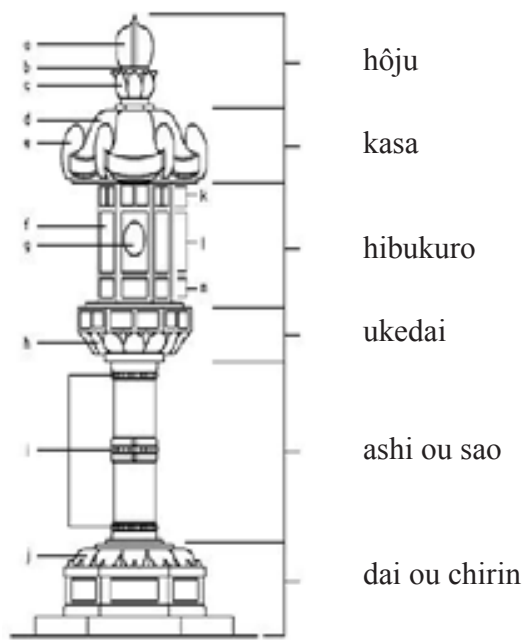

(9) Diagrama de uma Lanterna de Pedra. 

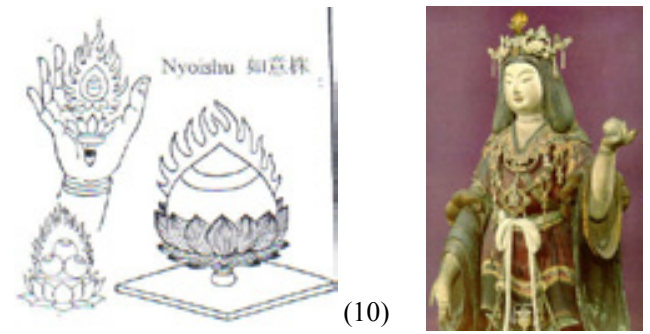

(11)
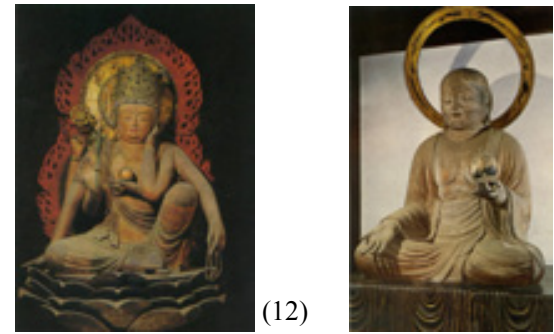

(10) Representações da joia hôju.

(11) Kichijôten, séc. XIII, madeira, 90 cm, Templo Jôruriji, Kyôto.

(12) Nyoirin Kannon, cerca do ano 836, madeira pintada, 108,8 cm, Templo Kanshinji, Ôsaka.

(13) Jizô Bosatsu, ano 868, madeira, 109,7 cm, Templo Kôryûji, Kyôto.
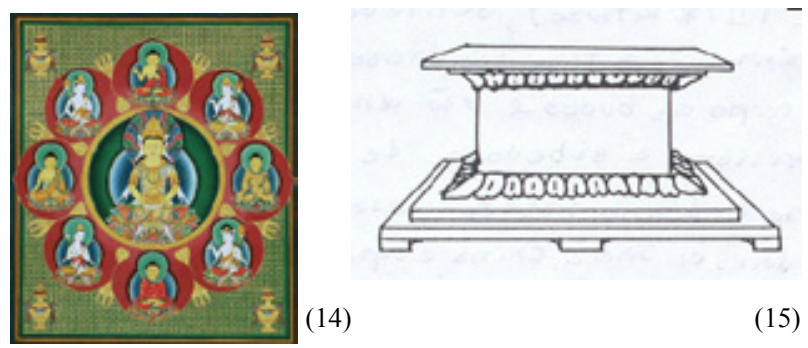

(15)

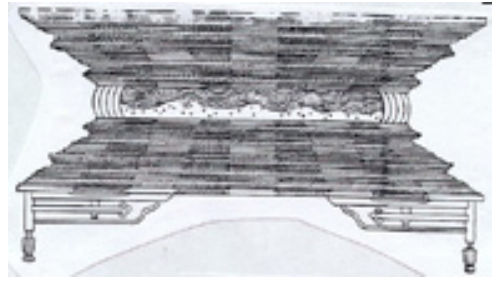

(16)

Oito lados representam os Oito Caminhos e as Oito Pétalas de Lótus onde estão os Oito Budas ao redor do Buda Central, Dainichi Nyorai.

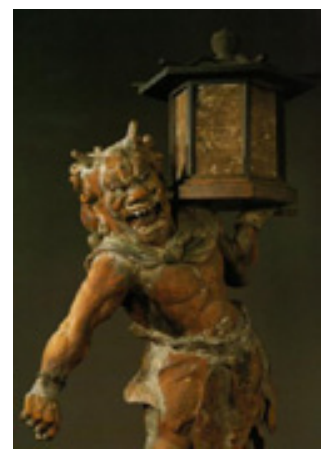

(17) 